\title{
Energy Efficiency of a Simulated Synthetic Natural Gas Combined Cycle (SNGCC)
}

\author{
Asfaw Gezae Daful, Zin Eddine Dadach* \\ Chemical \& Petroleum Engineering Department, Abu Dhabi Men’s College, Higher Colleges of Technology, Abu Dhabi, UAE \\ Email: ${ }^{\star}$ zdadach@hct.ac.ae
}

How to cite this paper: Daful, A.G. and Dadach, Z.E. (2021) Energy Efficiency of a Simulated Synthetic Natural Gas Combined Cycle (SNGCC). Journal of Power and Energy Engineering, 9, 42-53. https://doi.org/10.4236/jpee.2021.93003

Received: February 1, 2021

Accepted: March 28, 2021

Published: March 31, 2021

Copyright (c) 2021 by author(s) and Scientific Research Publishing Inc. This work is licensed under the Creative Commons Attribution International License (CC BY 4.0).

http://creativecommons.org/licenses/by/4.0/

\section{(c) (i) Open Access}

\begin{abstract}
The objective of this investigation is to analyze the impact of the flue gas recirculation (FGR) ratio on the different energy inputs and outputs of a SNGCC power plant as well as its overall efficiency. Simulation results indicate that increasing flue gas recirculation increases the energy consumed by the recirculation compressor and the energy produced by the gas turbine. On the other hand, it decreases the production of energy of the steam turbine and the energy consumed by the pump of the steam cycle. The overall energy efficiency of the SNGCC power plant is highest (41.09\%) at a value of 0.20 of the flue gas recirculation. However, the flue gas composition with a FGR ratio of 0.37 is more suitable for effective absorption of carbon dioxide by amine solutions. Based on the low heating value (LHV) of hydrogen, the corresponding overall efficiency of the power plant is $39.18 \%$ and the net power output of the plant is $1273 \mathrm{~kW}$ for consumption of $97.5 \mathrm{~kg} / \mathrm{hr}$. of hydrogen.
\end{abstract}

\section{Keywords}

Synthetic Natural Gas Combined Cycle, SNGCC, Energy Efficiency

\section{Introduction}

According to the U.S. Energy Information Administration, the burning of fossil fuels was responsible for 76 percent of U.S. greenhouse gas emissions in 2016 [1]. As natural gas (NG) is the cleanest fossil fuel for electricity production, gas-fired power generation plants are expected to play a significant role in order to reduce carbon dioxide emissions from the power generation sector. Moreover, because of the complementary temperature ranges of the Brayton GT cycle and the Rankine steam cycle, natural gas combined cycle (NGCC) can produce significantly improved thermodynamic cycle efficiency [2]. Besides its advantages 
related to the lowest carbon dioxide emissions, natural gas (NG) is also the recommended combustible because it reduces the operating cost of the plants by avoiding corrosion and other technical problems in the facilities caused by impurities such as $\mathrm{H}_{2} \mathrm{~S}, \mathrm{SO}_{\mathrm{x}}, \mathrm{NO}_{\mathrm{x}}$ and $\mathrm{HCl}$. However, the corresponding molar percentage of $\mathrm{CO}_{2}$ in flue gas is only about $3 \%-3.5 \%$ [3]. For an effective $\mathrm{CO}_{2}$ capture by amine solutions, it is recommended to obtain a molar percentage of $\mathrm{CO}_{2}$ in the flue gas around $10-15$ [4]. Consequently, the cost of $\mathrm{CO}_{2}$ capture from natural gas-fired power generation plants is high because of the large amount of energy needed in the stripper to obtain leaner amine. Compared to the heavier combustibles, the operating cost of the $\mathrm{CO}_{2}$ capture unit is also higher due to a higher concentration of oxygen responsible for amine degradation and corrosion problems. High Flue Gas Recirculation (FGR) ratios are therefore recommended in order to increase the $\mathrm{CO}_{2}$ concentration and decrease the $\mathrm{O}_{2}$ concentration in the flue gas to be treated in the absorption unit. The recirculated flue gas is often utilized as the secondary air (dilution air) to cool down the blades of the gas turbine.

The Natural Gas Combined Cycle (NGCC) power generation plant is the best technology to meet the ever-growing energy needs of the United Arab Emirates and reduce the country's environmental impact. However, even with the UAE's massive amount of proven natural gas reserves, the country still needs to import natural gas in order to satisfy the energy market. Utilizing carbon dioxide emissions for the production of synthetic natural gas (SNG) will therefore be valuable to contribute to the sustainable production of electricity in the United Arab Emirates. In light of this, a Synthetic Natural Gas Combined Cycle (SNGCC) power plant was introduced in a previous investigation and defined as a combined cycle plant where the fuel is synthetic natural gas (SNG) produced by a methanation reactor. The feed of the methanation reactor is the recycled stream of carbon dioxide of a $\mathrm{CO}_{2}$ capture unit treating the flue gas of the SNGCC power plant [5] [6]. As shown in Figure 1, the simplified SNGCC (Synthetic Natural Gas Combined Cycle) power plant is divided into eight different control volumes: (a) Air Compressor, (b) Combustor (CC), (c) Combustion Turbine Generator (GT), (d) Steam Turbine Generator (ST), (e) Heat Recovery Steam Generator (HRSG), (f) Condenser, (g) Pump and (h) Methanation reactor [6].

The objective of the first part of this investigation was to use Aspen Plus software and the Redlich-Kwong-Soave equation of state in order to simulate an adiabatic methanation reactor for the production of synthetic natural methane (SNG) using $1 \mathrm{~kg} / \mathrm{hr}$. of carbon dioxide [5]. In the second part of this study, Aspen plus software with SRK equation of state was utilized for the simulation of the Synthetic Natural Gas Combined Cycle (SNGCC). A simulation was performed in order to find the suitable percentage of the recycled flue gas for optimum conditions of the carbon capture unit of the power plant. Our results showed that with a recycling $37 \%$ of the flue gas, the concentration of $\mathrm{CO}_{2}$ and $\mathrm{O}_{2}$ of the flue gas entering the $\mathrm{CO}_{2}$ capture unit were respectively equal to $10.2 \%$ 


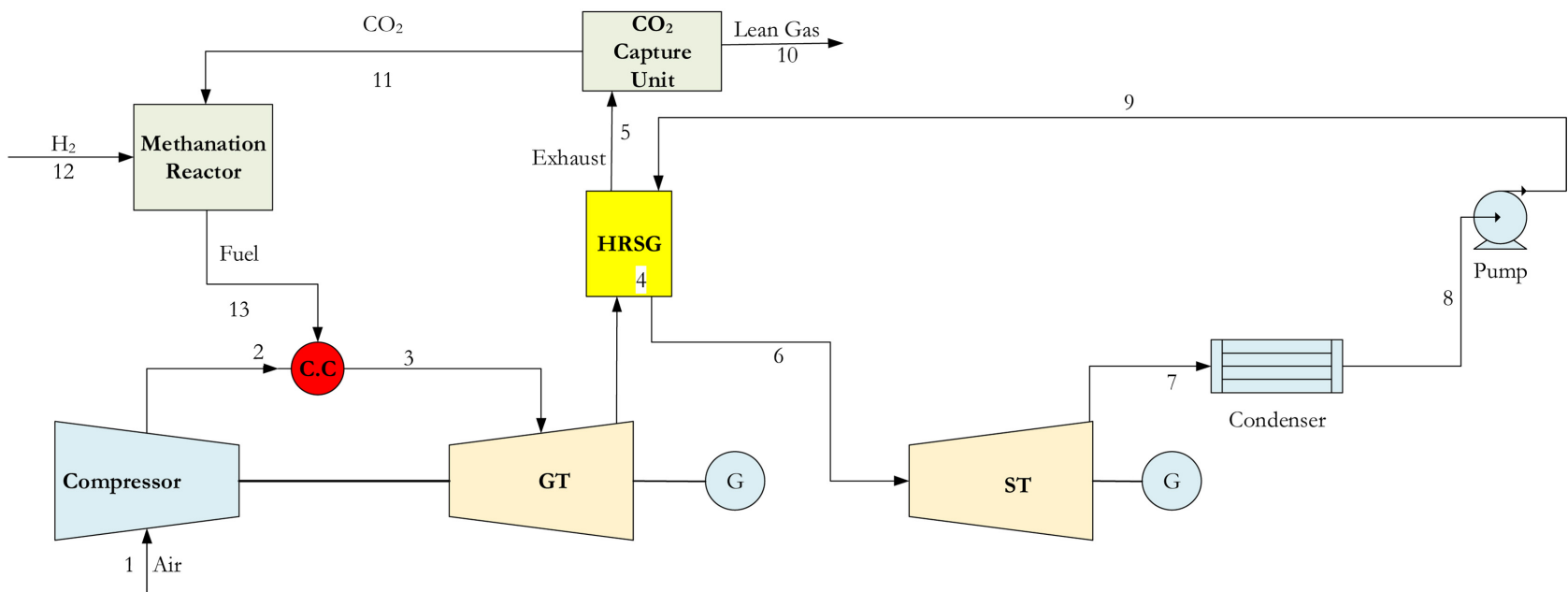

Figure 1. Schematic representation of a Synthetic Natural Gas Combined Cycle (SNGCC) [6].

and $2.01 \%$. It was concluded that the flue gas composition with a FGR ratio of 0.37 was suitable for effective absorption of carbon dioxide by amine solutions [6]. Since energy efficiency is the key parameter of energy conversion systems, the main objective of the third and last part of this investigation is to analyze the impact of flue gas recirculation on the different energy inputs and outputs of the SNGCC power plant and on its overall efficiency.

\section{Methodology}

\subsection{General Description of the Synthetic Natural Gas Combined Cycle (SNGCC) Power Plant}

Following the process flow diagram (Figure 1): (1) Fresh air enters the compressor. (2) It is then compressed to a higher pressure. Upon leaving the compressor, air enters the combustion system, where it is mixed with the Synthetic Natural Gas (13) produced by the methanation reactor where recycled carbon dioxide (11) from the carbon dioxide unit reacts with hydrogen (12). It is assumed in this paper that the hydrogen needed for the methanation of carbon dioxide is a product of a catalytic reforming plant that produces gasoline from heavy naphta fraction of an atmospheric distillation unit of crude oil.

The combustion process occurs essentially at constant pressure. The exhaust gas (3) leaves the combustor and enters the Combustion Turbine Generator (GT). In the turbine section, the flue gas is expanded to produce electricity. The flue gas leaves the GT at high temperature. In the second part of the SNGCC, the hot stream from the gas turbine (4) will generate steam in a Heat Recovery Steam Generator (HRSG). The steam cycle consists of a HRSG, Steam Turbine Generator (ST), condenser, and pump to form a Rankine cycle for electricity production. Water (9) enters the HRSG at high pressure and the resulting steam (6) produces electricity in the steam turbine generator (ST). The saturated steam (7) leaving the steam turbine is first condensed (8) and then its pressure increased (9) before returning to the HRSG. The exhaust gas (5) leaving the HRSG 
is treated in a $\mathrm{CO}_{2}$ capture unit where lean gas (10) is sent to the atmosphere. The de-aerator of the steam cycle is not included in this investigation.

\subsection{Process Description of the Simulated SNGCC Power Plant}

As shown in Figure 2, a Synthetic Natural Gas Combined Cycle (SNGCC) with a flue gas recirculation is divided in four main sections (Methanation reactor, Gas turbine, Steam turbine and $\mathrm{CO}_{2}$ capture unit):

\subsubsection{The Methanation Reactor}

The hydrogen gas needed for the methanation of carbon dioxide comes from a catalytic reforming of heavy naphta. The maximum production of methane of $0.875 \mathrm{kmol}$ per $\mathrm{kmol}$ of $\mathrm{CO}_{2}$ was obtained for the following operating conditions: $\left[\mathrm{H}_{2} / \mathrm{CO}_{2}\right]$ ratio of 3.5 , at relatively low temperature $\left(250^{\circ} \mathrm{C}-270^{\circ} \mathrm{C}\right)$ and high pressures 30 and $40 \mathrm{~atm}$. After removing water, the synthetic natural gas (SNG) produced by the methanation is utilized as the fuel for the gas turbine of the power plant.

\subsubsection{The Gas Turbine}

Fresh air at local atmospheric conditions $\left(40^{\circ} \mathrm{C}\right)$ is compressed up to 40 bars in a three-stage compressor with intercooling at $40^{\circ} \mathrm{C}$. The adiabatic efficiency of $85 \%$ is selected for the compressors [7]. SNG (Synthetic Natural Gas) mixes with fresh air in the combustor. It is assumed that combustion is complete and all the carbons in SNG converted to $\mathrm{CO}_{2}$.

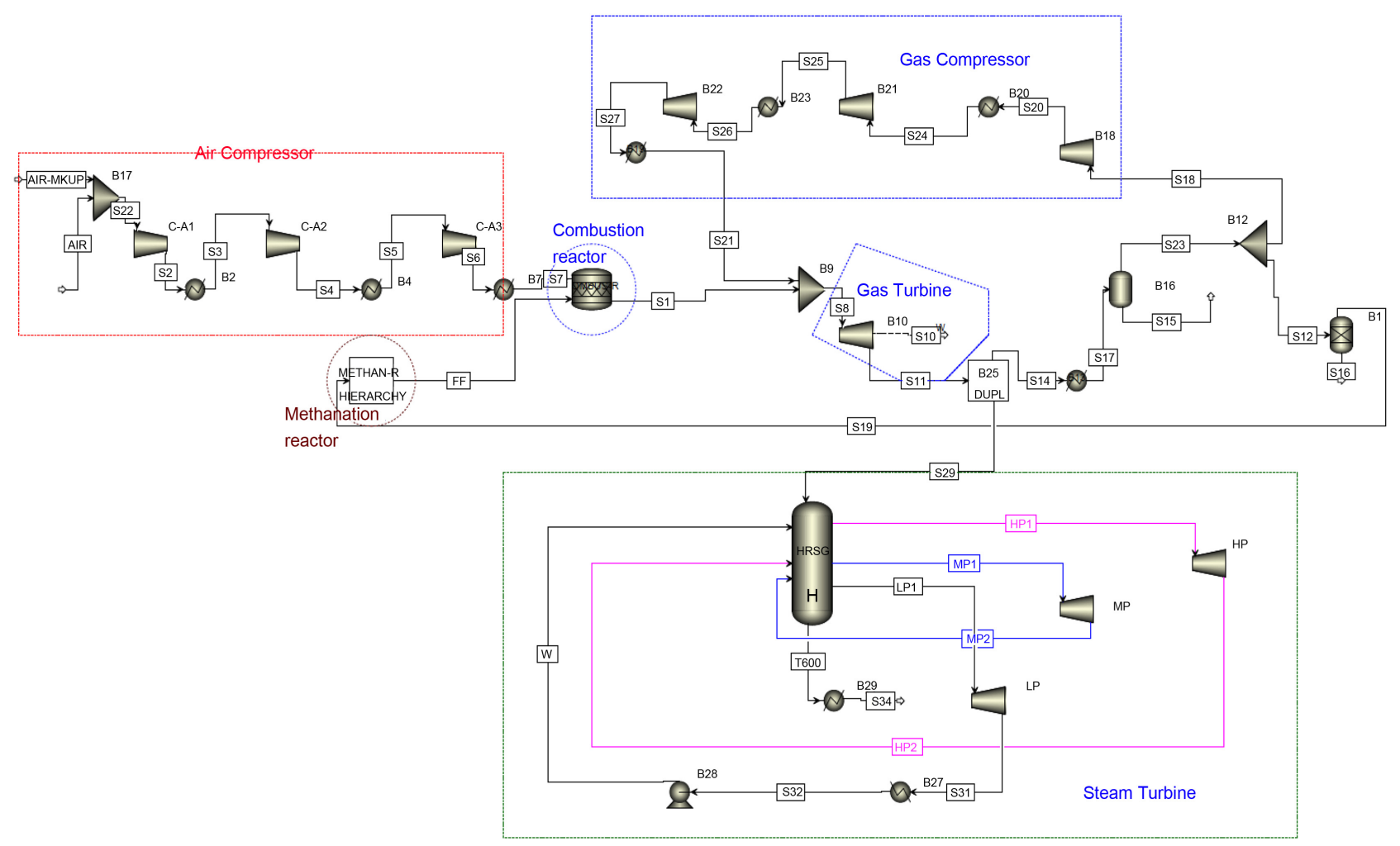

Figure 2. Simulated Synthetic Natural Gas Combined Cycle (SNGCC) power plant process flow sheet. 


\subsubsection{The Steam Turbine}

The exhaust gases leave the gas turbine at atmospheric pressure and high temperature. Flue gas enters the HRSG in order to produce steam at three levels of pressure: high pressure (HP) steam $\left(173 \mathrm{Bars}, 600^{\circ} \mathrm{C}\right)$, an intermediate pressure (IP) steam $\left(65\right.$ bars, $\left.565^{\circ} \mathrm{C}\right)$, and a low pressure (LP) steam $\left(2\right.$ bars, $\left.350^{\circ} \mathrm{C}\right)$ with double reheat. The adiabatic efficiency of the turbine, generator, and condensate pump is selected as $75 \%, 94 \%, 65 \%$ respectively [ 8$]$.

\subsection{4. $\mathrm{CO}_{2}$ Capture Unit}

The exhaust gas leaving the HRSG is cooled down until $40^{\circ} \mathrm{C}$ before being divided into two streams. The first stream is compressed and recycled to be mixed with the flue gas leaving the gas turbine to cool down the temperature of the stream before entering the gas turbine. The second stream is treated in a $\mathrm{CO}_{2}$ capture unit where lean gas is sent to the atmosphere. The resulting concentrated carbon dioxide $\left(95 \% \mathrm{CO}_{2}-5 \% \mathrm{H}_{2} \mathrm{O}\right)$ leaving the desorption column is recycled and utilized as the feed for the methanation process. For simplicity, the carbon dioxide capture unit is simulated as a column splitter.

\subsection{Simulation of the Effects of FGR Ratio on the Overall Efficiency of the SNGCC Power Plant}

Since energy efficiency is the key parameter of energy conversion systems, the impact of flue gas recirculation on the different energy inputs and outputs of the SNGCC power plant and on its overall efficiency are investigated. The objective is to compare the performance of equipment in the plant and the overall efficiency of the SNGCC power plant when the FGR changes from $1 \%$ to $37 \%$. For a typical Natural gas combined Cycle (NGCC), the fuel is methane. However, for the Synthetic Natural Gas Combined Cycle (SNGCC), the fuel is hydrogen entering the methanation reactor. Based on the Low Heating Value of hydrogen $(\mathrm{LHV}=119.96 \mathrm{MJ} / \mathrm{kg})$, the simulation results of the effects of the flue gas recirculation ratio (FGR) on the energies input and output of the power plant and its overall efficiency are shown in Table 1.

Table 1. Effects of FGR ratio on the energy streams of the power plant.

\begin{tabular}{ccccccc}
\hline FGR & $\begin{array}{c}\text { Total Energy } \\
\text { Input in kW } \\
\left(\mathrm{W}_{\mathrm{GT}}+\mathrm{W}_{\mathrm{ST}}\right)\end{array}$ & $\begin{array}{c}\text { Total Energy } \\
\text { Output in kW } \\
\left(W_{\text {Krecycle }}+W_{\mathrm{K}, \text { air }}+\right. \\
\left.W_{P}\right)\end{array}$ & $\begin{array}{c}\text { Total Net } \\
\text { Output } \\
\text { in kW }\end{array}$ & $\begin{array}{c}\text { Flow rate } \\
\text { of } \mathrm{H}_{2} \\
(\mathrm{~kg} / \mathrm{hr})\end{array}$ & $\begin{array}{c}Q_{\text {Hydrogen }} \\
\text { In kW }\end{array}$ & $\begin{array}{c}\text { Overall Energy } \\
\text { efficiency } \\
(\%)\end{array}$ \\
\hline 1 & 2535 & 814 & 1721 & 132.6 & 4418.5 & 38.95 \\
5 & 2537 & 846 & 1691 & 128.7 & 4288.6 & 39.43 \\
10 & 2540 & 891 & 1649 & 123.8 & 4125.3 & 39.97 \\
15 & 2541 & 941 & 1600 & 119.0 & 3965.3 & 40.40 \\
20 & 2559 & 997 & 1562 & 114.1 & 3802.1 & 41.09 \\
30 & 2552 & 1136 & 1416 & 104.3 & 3475.5 & 40.74 \\
37 & 2527 & 1254 & 1273 & 97.5 & 3248.9 & 39.18 \\
\hline
\end{tabular}




\subsubsection{Compressors}

In this study, fresh air at $40^{\circ} \mathrm{C}$ is compressed up to $3.1 \mathrm{MPa}$ in a three stage-compressor with intercooling at $40^{\circ} \mathrm{C}$. The pressure of the recycled gas is also increased from $110 \mathrm{kPa}$ to $3.1 \mathrm{MPa}$ using a three-stage compressor with intercooling at $40^{\circ} \mathrm{C}$. After leaving the Heat Recovery Steam Generator (HRSG), the flue gas is cooled to $40^{\circ} \mathrm{C}$ before being recycled as a cooling system for the gas turbine. Therefore, the pressure of the recycled flue gas is increased from 1 bar to 40 bars using a three-stage compressor with intercooling at $40^{\circ} \mathrm{C}$.

Figure 3 shows a linear relationship between the energy consumption of both compressors. However, our simulation results indicate that the power consumption for the air compressor is almost constant at around $735 \mathrm{~kW}$. As expected, the flue gas recirculation ratio increases (slope $=12.46$ ) the energy needed for the compression of the recycled flue gas.

\subsubsection{Steam Cycle}

The steam cycle contains High Pressure, Intermediate Pressure and Low Pressure stages with two reheats. The effects of the flue gas recirculation on the production of electricity by the steam turbine and the energy consumed by the pump of the water of the steam cycle are shown in Figure 4 and Figure 5.

Figure 4 indicates a linear relationship between the energy produced by the steam turbine and the value of the flue gas recirculation (FGR) ratio. Increasing the flue gas recirculation has negative effects (slope $=-4.35$ ) on the energy produced by the steam turbine because less heat is available in the Heat Recovery Heat Generator (HRSG).

Figure 5 shows that flue gas recirculation has a small negative effect (slope $=$ -0.3 ) on the energy consumption of the water pump of the steam cycle.

\subsubsection{Gas Turbine}

The net output of the gas turbine increases with the temperature of the exhaust gas but it is limited by the metallurgical limitation for the gas turbine being utilized. The effects of Flue Gas Recirculation (FGR) ratio on the temperature of

Effects of FGR on the Total Energy Comsuption of Compressors (kW)

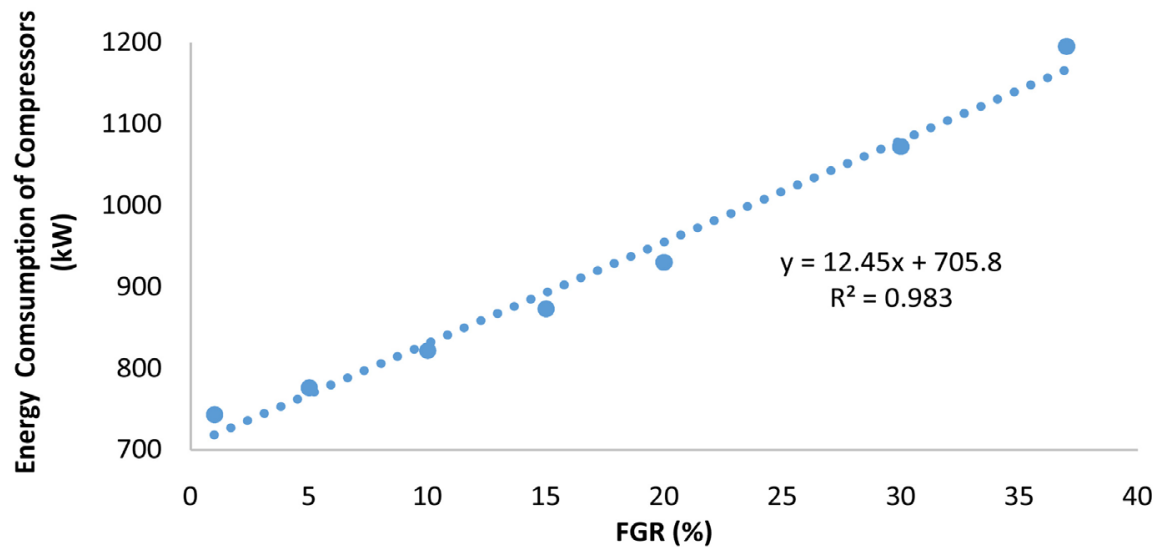

Figure 3. Effects of FGR ratio on energy consumption of compressors. 


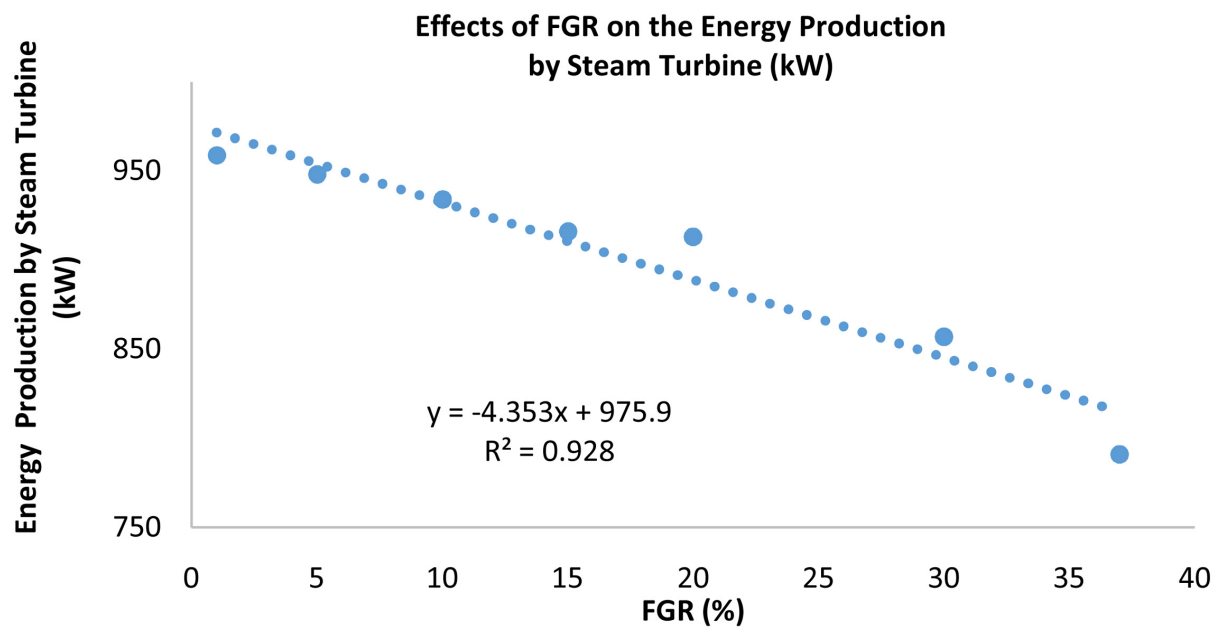

Figure 4. Effects of FGR ratio on energy production by the steam cycle.

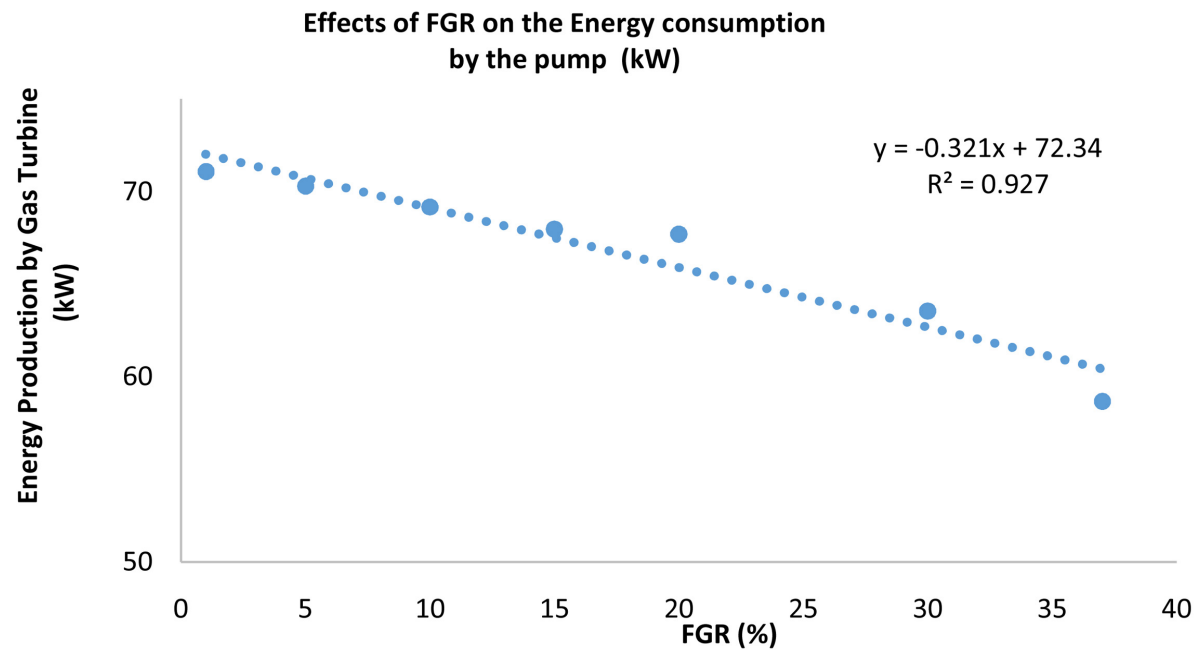

Figure 5. Effects of FGR ratio on energy consumption by the water pump.

the exhaust gas leaving the combustor are therefore investigated and the simulation results are shown in Figure 6.

As expected, Figure 6 shows that the flue gas recirculation decreases linearly (slope $=-13.34)$ the temperature of the flue gas entering the gas turbine. In a gas turbine, the blades have a metallurgical limitation and the temperatures could vary from $800^{\circ} \mathrm{C}$ to $1700^{\circ} \mathrm{C}$ depending on their materials and whether or not they have cooling systems.

Based on the information in Figure 7, the temperature $1500^{\circ} \mathrm{C}$ (G-type Turbine) is used in this study as the metallurgical limitation of the turbine. The effects of flue gas recirculation on the power generated by the gas turbine are shown in Figure 8.

Figure 8 shows a linear relationship between the energy produced by the gas turbine and the value of the flue gas recirculation (FGR) ratio. The flue gas recirculation ratio has positive effects (slope $=4.42$ ) on the energy produced by the gas turbine. 


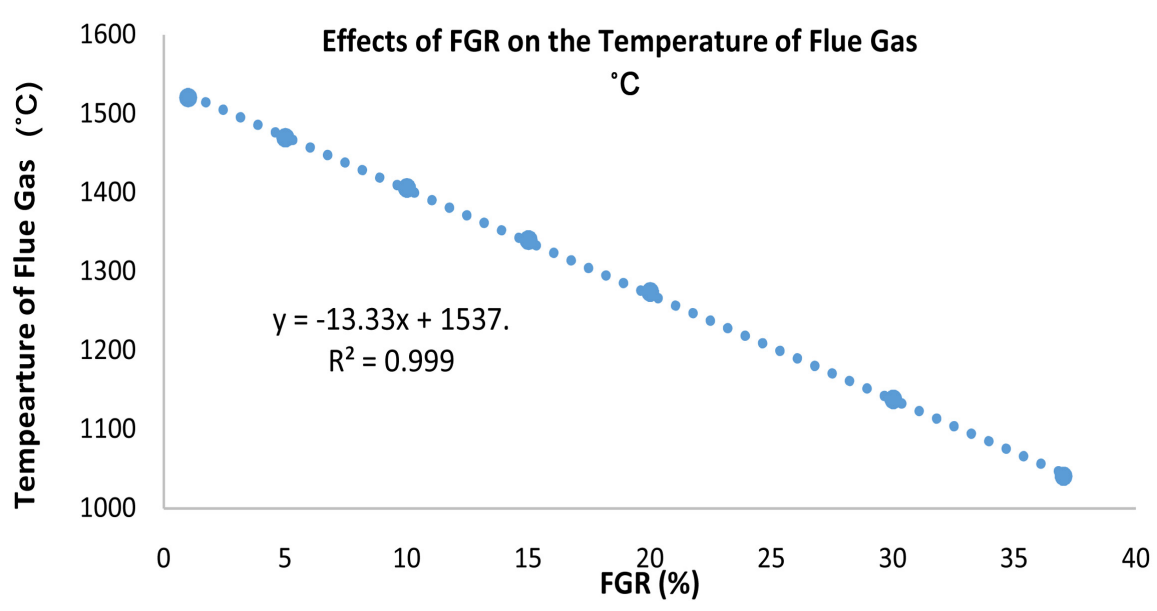

Figure 6. Effects of FGR ratio on the temperature of flue gas.

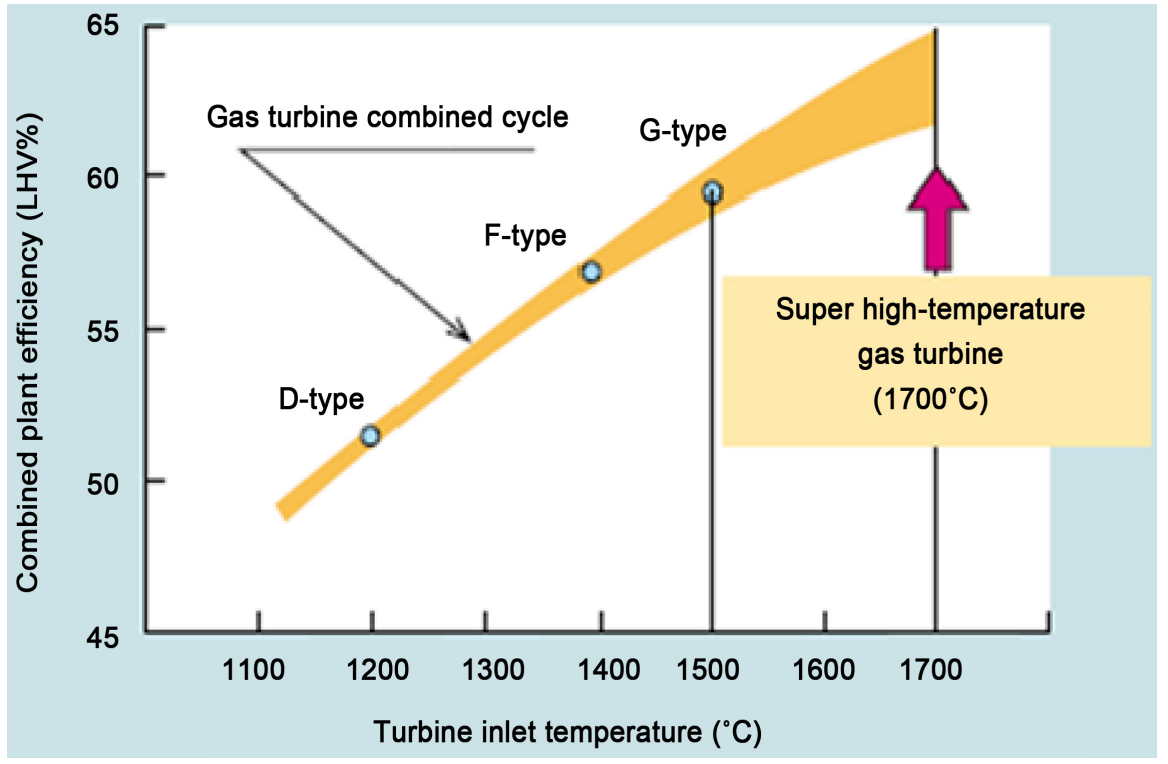

Figure 7. Turbine inlet temperature and combined plant efficiency [7].

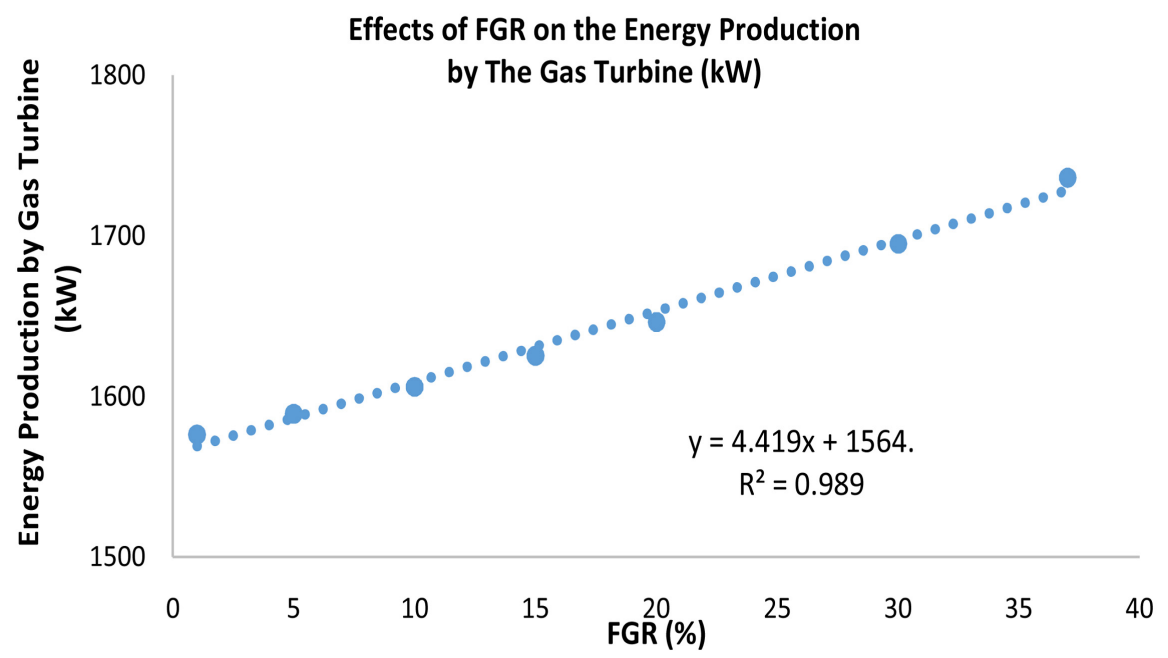

Figure 8. Effects of FGR ratio on the power generated by the gas turbine. 


\section{Effects of FGR Ratio on the Overall Efficiency of the SNGCC Power Plant}

Synthetic Natural Gas Combined Cycle (SNGCC) power generation is an energy conversion system of generating electric power that combines gas turbine power generation (CTG) with steam turbine power generation (STG). The thermodynamic power cycles can be categorized as gas cycles and steam cycles. Gas turbines operate using the principles of the Brayton cycle. The isentropic efficiency $\left(\eta_{\text {iso }}\right)$ of the Brayton cycle can be expressed in terms of the temperatures and pressures entering $\left(P_{1} \& T_{1}\right)$ and leaving $\left(P_{2}, T_{2}\right)$ the compressor:

$$
\eta_{\text {iso }}=1-\frac{T_{1}}{T_{2}}=1-\left(\frac{P_{1}}{P_{2}}\right)^{\frac{k-1}{k}}
$$

where $k$ is the specific heat ratio. Based on Equation (1), increasing the temperature of the stream of gas leaving the compressor or increasing the pressure ratio will enhance the efficiency of the gas turbine. In this investigation, fresh air enters the compressor at $40^{\circ} \mathrm{C}$ and the temperature of the exhaust gas is limited to $1500^{\circ} \mathrm{C}$. Based on these operating conditions, the isentropic efficiency of the gas turbine is 0.82 . This value was selected as the adiabatic efficiency of the gas turbine for the simulation of the synthetic natural gas combined cycle. The overall efficiency of the gas turbine could be estimated by the following equation:

$$
\eta=\frac{W_{\text {net output }}}{m_{\mathrm{SNG}} \times \mathrm{LHV}}
$$

where $W_{\text {net output }}$ is the difference between the energy produced and the energy consumed by the different equipment of the combustion turbine generator (CTG), $m_{\mathrm{SNG}}$ is the mass flowrate of synthetic natural gas and LHV is the low heating value of natural gas. The hot stream (exhaust gas) is then utilized to produce more electricity by generating steam in the Heat Recovery Steam Generator (HRSG). A steam turbine in a combined cycle power plant operates using the principles of the Rankine cycle. Like the Brayton cycle, the ideal Rankine cycle operates on four internally reversible processes. The theoretical maximum efficiency of a Rankine cycle is the Carnot efficiency given in Equation (3).

$$
\eta_{\text {Carnot }}=1-\frac{T_{\text {Cold }}}{T_{\text {Hot }}}
$$

The thermal efficiency of a Rankine cycle is lower than that of a Carnot cycle operating between the same temperature levels. This is primarily because of the fact that the energy transfer as heat in the boiler does not take place at constant temperature in the Rankine cycle. The purpose of a reheating cycle is to remove the moisture carried by the steam at the final stages of the expansion process and improves the efficiency of the cycle, because more of the heat flow into the cycle occurs at higher temperatures.

Based on Figure 9, the thermal efficiency of the Rankine cycle with reheat is given by Equation (4): 


$$
\eta=\frac{\left(h_{1}-h_{2}\right)+\left(h_{3}-h_{4}\right)+\left(h_{6}-h_{5}\right)}{\left(h_{1}-h_{6}\right)+\left(h_{3}-h_{2}\right)}=\frac{W_{\text {net-out }}}{Q_{\text {in }}}
$$

As shown in Figure 10, because of the complementary temperature ranges of the Brayton GT cycle and the Rankine steam cycle, synthetic natural gas combined cycle (SNGCC) can produce significantly improved thermodynamic cycle efficiency. Based on the simulation results (Table 1), the overall energy efficiency of the SNGCC power plant was highest (41.09\%) at a value of $20 \%$ of the flue gas recirculation (FGR) ratio. The molar composition of $\mathrm{CO}_{2}$ and $\mathrm{O}_{2}$ with circulation ratios of 0.37 and 0.20 are compared in Table 2 .

\section{The Ideal Reheat Rankine Cycle}
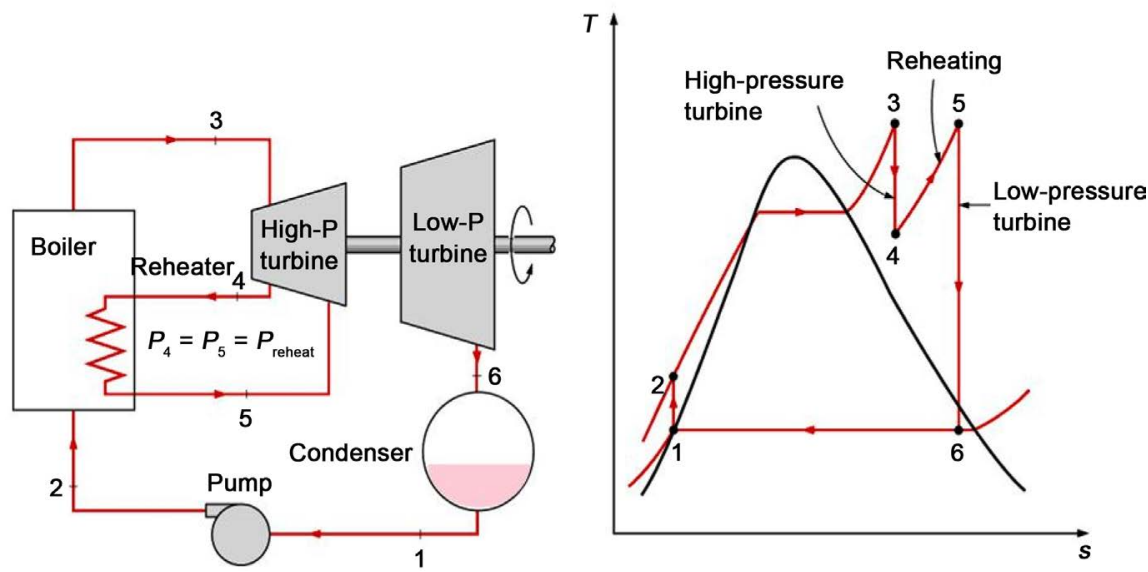

Figure 9. Ideal reheat rankine cycle [9].

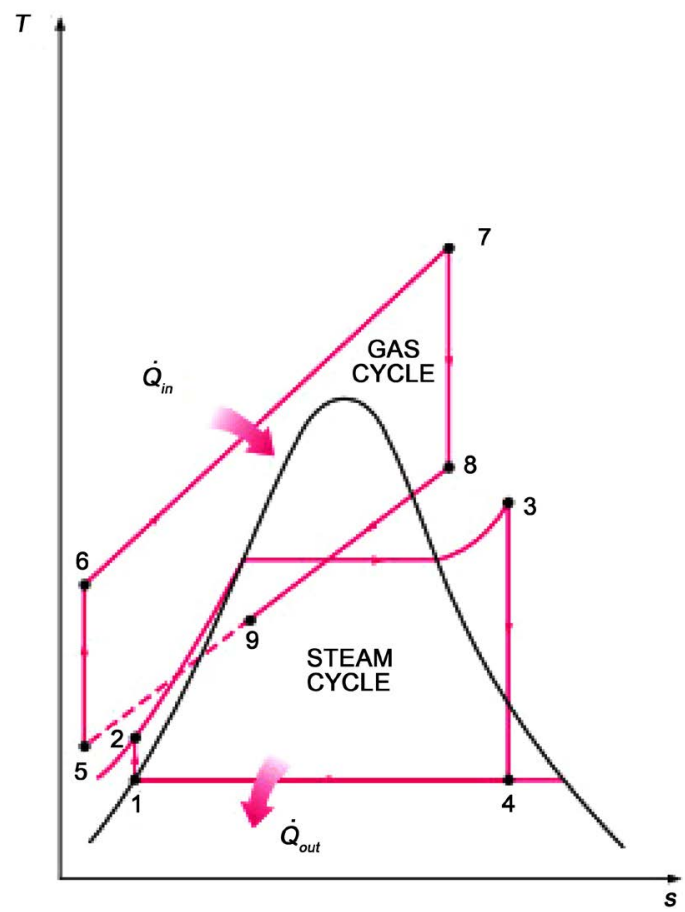

Figure 10. T-S diagram of NGCC cycle [2]. 
Table 2. Molar composition of flue gas without recirculation and with a FGR ratio of 0.42 .

\begin{tabular}{ccc}
\hline Component (\%) & FGR $=0.37$ & FGR $=0.20$ \\
\hline $\mathrm{CO}_{2}$ & 10.2 & 7.0 \\
$\mathrm{O}_{2}$ & 2.01 & 6.9 \\
\hline
\end{tabular}

It should be noted that the requirements of the composition of flue gas needed for effective absorption of the $\mathrm{CO}_{2}\left(\mathrm{CO}_{2} \geq 10 \%\right.$ and $\left.\mathrm{O}_{2}<5 \%\right)$. Based on the results shown in Table 2, the most suitable composition of the flue gas for capturing carbon dioxide by amines is at the value of FGR ratio of $37 \%$.

\section{Discussion}

Figure 3 indicates a linear relationship between the FGR ratio and the energy consumption of the compressor. As expected, it was observed that the flue gas recirculation (FGR) ratio increased the energy needed for the compression of the recycled flue gas. On the other hand, our simulation outputs indicate that the power consumption for the air compressor was almost constant at around 735 $\mathrm{kW}$. For the stream cycle, the flue gas recirculation decreased both the energy produced by the steam turbine and the energy consumed by the pump. However, the effects on the water pump were much smaller (Figure 4 and Figure 5). For the gas turbine, the metallurgical limitation of the gas turbine was fixed at $1500^{\circ} \mathrm{C}$ in this investigation. As expected, the flue gas recirculation decreased the temperature of the flue gas entering the gas turbine (Figure 6) and increased the energy produced by the gas turbine (Figure 8).

As shown, in Table 1, the flue gas recirculation increased the overall efficiency of the plant to $41.09 \%$ at $20 \%$ FGR ratio. From higher values of FGR, the effects are negative. However, from the simulation results shown in Table 2, it is expected to have less efficient carbon dioxide absorption $(7<10 \%)$. Moreover, it is also expected to have more corrosion problems in the carbon capture plant because the molar fraction of oxygen is higher than the limit value of $5 \%$.

\section{Conclusion}

The objective of this third part of the investigation related to the proposed Synthetic Gas Combined Cycle (SNGCC) is to analyze the impact of the flue gas recirculation (FGR) ratio on the different energy inputs and outputs of the power plant as well as its overall efficiency. It can be concluded that: 1) the flue gas composition with a FGR ratio of 0.37 is the most suitable for effective absorption of carbon dioxide by amine solutions. 2) Based on the low heating value (LHV) of hydrogen, the overall efficiency of the power plant is 39.18\%. 3) The power plant has a total net output of $1273 \mathrm{~kW}$ for consumption of $97.5 \mathrm{~kg} / \mathrm{hr}$. of hydrogen.

\section{Acknowledgements}

The authors wish to thank the higher colleges of technology of the UAE for 
supporting this research project.

\section{Conflicts of Interest}

The authors declare no conflicts of interest regarding the publication of this paper.

\section{References}

[1] U.S. Energy Information Administration (2020) Monthly Energy Review, Environment, Preliminary Data. https://www.eia.gov/totalenergy/data/monthly/

[2] Beér, J.M. (2007) High Efficiency Electric Power Generation: The Environmental Role. Progress in Energy and Combustion Science, 33, 107-134. https://doi.org/10.1016/j.pecs.2006.08.002

[3] Al Wahedi, F.S.A.A. and Dadach, Z.E. (2013) Cost Effective Strategies to Reduce $\mathrm{CO}_{2}$ Emissions in the UAE: A Literature Review. Industrial Engineering \& Management Journal, 2, 1-9.

[4] Akram, M., Khandelwal, B., Blakey, S. and Wilson, C.W. (2013) Preliminary Calculations on Post Combustion Carbon Capture from Gas Turbines with Flue Gas Recycle. Proceedings of ASME Turbo Expo 2013: Turbine Technical Conference and Exposition, San Antonio, Texas, USA, 3-7 June 2013, 6 p. https://doi.org/10.1115/GT2013-94968

[5] Daful, A.G. and Dadach, Z.E. (2019) Simulation of a NGCC Power Generation Plant for the Production of Electricity from $\mathrm{CO}_{2}$ Emissions Part I: The Methanation Reactor. Journal of Power and Energy Engineering, 7, 1-14. https://doi.org/10.4236/jpee.2019.77001

[6] Daful, A.G. and Dadach, Z.E. (2020) Simulation of a NGCC Power Generation Plant for the Production of Electricity from $\mathrm{CO}_{2}$ Emissions Part II: SNGCC Power Plant. Journal of Power and Energy Engineering, 8, 53-62.

https://doi.org/10.4236/jpee.2020.88004

[7] Ishikawa, M., Terauchi, M., Komori, T. and Yasuraoka, J. (2008) Development of High Efficiency Gas Turbine Combined Cycle Power Plant. Mitsubishi Heavy Industries, Ltd. Technical Review, 45, 15-17.

[8] Allahyari, N. (2013) Economic Evaluation of Capturing $\mathrm{CO}_{2}$ from Natural Gas Power Plant and Injecting $\mathrm{CO}_{2}$ for Enhanced Oil Recovery as an Integrated System. Master's Theses, University of Regina, Canada.

[9] Rankine Cycle in Wikipedia. https://en.wikipedia.org/wiki/Rankine_cycle 